\title{
Preface to Volume 25(2)
}

\section{Twenty five years of ORiON}

Twenty Five years! Can it be?

From the founding of ORSSA in 1969, one of the aims of the new society was to establish a journal of its own, but for some years this was little more than a pipe dream. Then in the early 1980s, the executive approached me to set up a one-person committee of enquiry into the establishment of an OR journal in South Africa.

I must confess that at the time my first concern was whether there would be enough critical mass of publishable material to maintain a viable quality ORSSA journal, and I explored a number of potential joint ventures with other groups. At least one possibility I recall investigating was that of a joint OR and Computer Science journal along the lines of the then very successful Canadian INFOR journal. However, there seemed to be no takers for such joint ventures, and I had to apply my mind to what the OR community alone could support. After consultation with many colleagues and some paper and pencil calculations, I advised the ORSSA executive that:

- It would be feasible to sustain two issues a year with 3 or 4 papers per issue, especially if we included a few special issues on selected themes from time to time.

- We should not try to compete with existing journals, but should project a distinct image as a repository for applications in Africa or more broadly in the developing world. (I still think that this a role that ORiON could better project, especially with the growing interest in OR for Development!)

- Under such conditions, the journal could well provide many benefits to the membership of ORSSA.

My recommendation was thus that ORSSA should move to establish its own journal, but I talked myself into a job! In accepting my recommendation, the executive also invited me to become the first editor, a challenge which I could not easily refuse, but accepted with some trepidation! So ORiON was born. It was not an easy birth, as I was in the throes of a major relocation from Pretoria to Cape Town. I did have the parental privilege of naming the child, although I suspect that some have forgotten the origins of the name as both

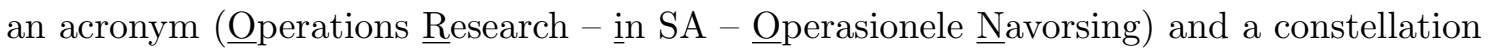
symbolizing the Southern skies.

We published 8 papers in Volume 1 of 1985 . It is interesting to recall the content:

- Constrained regression models for optimization and forecasting (PJS Bruwer \& JM Hattingh)

- A holistic approach to planning agricultural development: A comparative study of Taiwan and Transkei (TJ Pembridge)

- A mathematical model for residential planning in Richards Bay (MJ Joubert) 
- A comparison of economic decision making using net present value analysis versus present value ratio combined with a minimum hurdle rate (RED Woolsey \& $\mathrm{CE}$ Lienert)

- The assignment of workers to tasks - An example from an academic department (M Sinclair)

- Multi-product allocation and distribution (DC Currin \& HW Ittmann)

- Constraints to optimal land use in Ciskei (DR Tapson)

- Assessment of technologies in a global energy system (PJ Vermeulen)

In reflecting back, I am pleased to notice that we had already then achieved a combination of softer and harder OR methods, and a wide range of real local applications in agriculture, land-use development, personnel planning, logistics and energy. All of these issues are surely relevant to life in 2009, especially in the developing world context. I am sure that the present editor would be happy to see papers on these themes today!

If the child ORiON had a difficult birth, it also went through turbulent periods of adolescence. There were times when it was difficult to maintain a good flow of quality submissions, to sustain the required level of publication. It is a tribute to the editors who came after me (see Table 1) and their supporting business managers, that they never wavered in their dedication to the task, to securing submissions of high quality. All added their own innovations and important new thrusts, but it is under the guidance of the current editor, Jan van Vuuren, that ORiON now seems truly to have reached maturity, with a fully international image and a good flow of papers. Volume 24 contained application papers related to defence, politics, personnel management, health planning, and fisheries and wildlife management. Such applications continue the original aims and are witness to the health of OR in South Africa.

\begin{tabular}{lc}
\hline Editor & Tenure \\
\hline Theodor Stewart & $1985-1989$ \\
Marius Sinclair & $1990-1993$ \\
Yvonne Walus & $1994-1995$ \\
Paul Fatti & $1995-2003$ \\
Jan van Vuuren & $2004-2009$ \\
\hline
\end{tabular}

Table 1: Editors of ORiON.

Quo Vadis? Where will ORiON be in another 25 years' time? There are a number of pressures facing any journal today. There is the continual debate around the value of printed versus electronic journals, and this debate is far from over. We are still waiting for really creative ideas in this context, and ORiON may have to adapt to new ideas. Journals are increasingly being judged by "impact factors" created by bean-counters from superficial counts of numbers of citations. Oh, how I wish I could give them a course in multicriteria decision analysis to really assess impact! A particular problem with journals emphasizing applications is that these are read mainly by practitioners who do not often publish themselves, so that citations may be low even when practical impact is high. Once again, we look for creative ideas for recognizing the value, or impact, of contributions to real-world applied OR in ORiON. 
Following on from the previous paragraph, I would like to end this preface with a return to my earlier plea. Should we not seek to position ORiON as the international medium of choice for publications in OR for Development? This does not imply that other contributions would be unwelcome, but would recognize that ORSSA has played a leading role in IFORS and EURO in promoting the concept of OR for Development. Emerging out of the 2009 ORSSA conference there is an initiative to set in motion a major thrust by ORSSA into these and related application areas. I sincerely hope that ORiON can share this vision with the world.

Best wishes for the next 25 years!

Theo Stewart (Founding Editor)

December 2009 